\title{
Entre fotografias científicas e a ciência da fotografia
}

\author{
Wagner Souza e Silva*
}

\begin{abstract}
SOUZA E SILVA, W. Entre fotografias científicas e a ciência da fotografia. Revista do
\end{abstract} Museu de Arqueologia e Etnologia, São Paulo, 17: 435-444, 2007.

Resumo: Tendo como referência alguns projetos desenvolvidos junto ao Museu de Arqueologia e Etnologia da Universidade de São Paulo, o presente texto tem os objetivos de apontar questionamentos a respeito da prática da fotografia como ferramenta de apoio à pesquisa, e propor seu uso de forma mais abrangente a partir da análise de sua configuração como imagem técnica.

Palavras-chave: Fotografia - Ciência - Tecnologia - Imagens técnicas.

\section{Introdução}

$\mathrm{O}$ conhecimento contemporâneo vem sendo não só constituído por meio do diálogo entre textos e imagens, mas também pelos procedimentos de divulgação e proliferação de métodos, idéias e conceitos garantidos pelas tecnologias disponíveis para isso. Hoje, inevitavelmente, a ciência deve dialogar com os avanços que ela mesma proporciona em diversas áreas tecnológicas, sendo que seu próprio conceito, muitas vezes, acaba por se confundir com o próprio conceito de tecnologia, revelando a indissociabilidade existente entre ambos (Cavalheiro 2007). A fotografia, como tecnologia consagrada e aplicada em inúmeros setores da ciência, é um indício dessa associação.

A ciência, como busca de entendimento da realidade, baseia seus métodos, grosso modo, em observar e anotar o que se vê ou o que pode, de alguma forma, ser medido e calculado, visando

(*) Seção de Produção Gráfica e Áudio-Visual do Museu de Arqueologia e Etnologia da Universidade de São Paulo.wasosi@usp.br estipular seus modelos e suas regras. Nesse sentido, a fotografia surge como uma prática extremamente útil quando há a necessidade de demonstração do objeto de estudo e seu uso é constante e em larga escala como forma de apoio às diversas esferas da pesquisa. Este apoio se dá através da inegável objetividade presente nas fotografias, as quais são consideradas perfeitas imagens analógicas construídas por mecanismos precisos, e que, potencialmente, podem atender aos rigores e critérios que necessariamente são fundamentais para garantir a credibilidade do tema pesquisado. Das experiências cronofotográficas de análise do movimento de Eadward Muybridge e Etienne-Jules Marey, ao final do século XIX, às imagens obtidas por sistemas robóticos no planeta Marte no início deste século, a fotografia se faz presente e seu uso é recorrente em diversas áreas de pesquisa, tais como biologia, antropologia, arqueologia, astronomia, entre inúmeras outras.

Na prática de produção das fotografias científicas, por mais que se reconheça a participação do sujeito (aquele que opera o equipamento) em sua construção, o que se procura é a idéia de a etapa da formação da imagem não sofrer 
intervenção do homem, o que ocorre tanto no processo convencional quanto no digital. $\mathrm{O}$ exato momento em que a luz atinge os sais de prata de uma película ou a placa de fotodiodos de uma câmera digital deve ser isolado de qualquer interferência externa. Qualquer ajuste ou intervenção somente pode ser efetuado nos momentos anteriores ao contato da luz com a superfície formadora da imagem. E talvez resida aí a principal característica objetiva da câmera fotográfica: este instante preciso, ou seja, a fotografia propriamente dita (foto/luz e grafia) escrita) é um processo totalmente automático. Por mais que se apontem as interferências do fotógrafo, desde as mais elementares como a escolha do enquadramento ou o ajuste do foco, até as mais elaboradas, como o tipo de suporte ou objetiva (lentes), sempre existirá uma certa espontaneidade atribuída ao aparato na formação da imagem fotográfica.

A idéia da fotografia como documento (do latim documentum, que deriva de docere "ensinar/ demonstrar”), é reforçada por esse automatismo. No âmbito de qualquer pesquisa científica que busca evidenciar e certificar o objeto de estudo por meio da fotografia, procura-se justamente a imparcialidade do operador da câmera fotográfica, sendo que qualquer ajuste deve respeitar unicamente os objetivos pretendidos pelo estudo. É assim que se garante à fotografia o status de imagem documental. A possibilidade de comprovação ou certificação presente na prática da fotografia reside, portanto, em suas atribuições derivadas de seu aspecto de técnica automatizada, que carrega em si uma certa autonomia de trabalho.

Por essa razão, as imagens fotográficas foram inauguradoras de uma nova forma de classificação das imagens que são produzidas de forma automática, passando, portanto, a ser reconhecidas como imagens técnicas, tais como aquelas que vieram também a ser produzidas pelo cinema, vídeo e, mais atualmente, pelos processos infográficos do universo digital. É claro que o distanciamento que se provoca entre sujeito e máquina nessa idéia de técnica deve-se muito mais à conotação contemporânea que o termo adquiriu. A idéia de técnica, hoje, encontra-se impregnada pela idéia de tecnologia difundida como desígnio direto das máquinas e instrumentos complexos que trazem um caráter inovador e, muitas vezes, deslumbrante. Devido aos recorrentes avanços tecnológicos em inúmeras áreas da vida humana, o termo tecnologia, principalmente para o senso comum, adquiriu uma significação muito mais estrita que a amplitude do "saber e fazer" poderia abarcar (Dubois 2004: 31). Dessa maneira, outras formas mais simples de tecnologias, tais como uma roda, uma lâmina ou mesmo uma alavanca, por exemplo, tendem a ser não classificadas como artefatos técnicos, principalmente por não trazerem em suas estruturas as tecnologias (aqui já entendidas em sua acepção contemporânea) compostas por sistemas eletrônicos complexos ou que carregam em si um caráter "novidadeiro". Qualquer "imagem materializada em algum tipo de suporte é o resultado de aplicação de algum tipo de técnica de representação pictórica”, mas o que se entende hoje por imagem técnica corresponde muito mais a "um campo de fenômenos mais típico de nosso tempo", em que a intervenção de tecnologias recentes "afeta substancialmente a natureza mesma da imagem” e a insere dentro de paradigmas que nos parecem novos ou inéditos, embora nem sempre o sejam necessariamente" (Machado 2002: 223). No caso da fotografia não poderia ser diferente, já que os aprimoramentos técnicos recorrentes a tornam uma amostra evidente deste cenário tecnotrônico baseado num consumismo recorrente de novidades tecnológicas. A prática da fotografia, portanto, produz imagens técnicas.

\section{Fotografias como imagens técnicas}

Mas a designação da fotografia como imagem técnica encontra muito mais profundidade quando analisada sob a óptica de Vilém Flusser, considerado o precursor desta forma de classificação. Flusser procura ressaltar justamente a objetividade presente na estrutura da imagem fotográfica a partir de sua estreita relação com os conceitos de técnica e tecnologia, entendidos agora de forma mais abrangente (1985). Ao analisar a estrutura da imagem fotográfica em qualquer que seja a sua aplicação, o pensamento 
de Flusser revela-se motivador para suscitar alguns apontamentos a respeito da produção fotográfica de apoio à ciência, principalmente pela forma com que constrói a relação entre técnica, fotografia, imagem e conhecimento.

Para compreender a dimensão do papel que a fotografia cumpre - não só na esfera científica, mas também em outras aplicações - torna-se fundamental entender, antes de tudo, como Flusser contextualiza a criação da técnica da fotografia na História, a partir da análise da relação entre texto e imagem. Para o autor, o surgimento da escrita no segundo milênio a.C. tinha o objetivo de combater a idolatria das imagens, uma vez que a capacidade do homem para decifrá-las, a imaginação, passava a ser substituída por alucinação. Em outras palavras, as imagens, mediadoras da relação do homem com o mundo, não só deixavam de representálo, mas passavam a escondê-lo. O homem perdia a visão do mundo concreto e "ao invés de se servir das imagens em função do mundo, passava a viver em função das imagens". A escrita, portanto, visando traduzir cenas em conceitos, "rasgava" as imagens para o homem ir ao encontro do mundo. Mas a crise seria inevitável uma vez que estes conceitos, ao representarem as imagens, que por sua vez representavam o mundo, tornavam-se cada vez mais difíceis de serem decifrados e cada vez mais inimagináveis. "O texto tampa imagens que tampam o mundo", e "ao inventar a escrita, o homem se afastou ainda mais do mundo concreto quando, efetivamente, pretendia dele se aproximar". Surge a textolatria, "fidelidade ao texto", tão alucinatória quanto a idolatria e que, para Flusser, pode ser facilmente constatável em ideologias e nas ciências exatas do século XIX. Exatamente o momento em que surge a fotografia que, para o autor, busca ultrapassar a "crise dos textos" (op.cit.:13-17).

Imagens técnicas são frutos de textos científicos aplicados, afirma Flusser, e a fotografia inaugurou tal possibilidade. Toda a tecnologia que se materializa nos aparelhos que permitem a produção de imagens é proveniente dos séculos de aprimoramento da escrita e, conseqüentemente, dos textos e conceitos. "Imagens tradicionais precedem os textos por milhares de anos" (como as pinturas rupestres), e "as imagens técnicas sucedem aos textos altamente evoluídos” (ciências exatas). "Ontologicamente, as imagens imaginam o mundo e as imagens técnicas imaginam textos que imaginam o mundo" (op.cit.: 19).

E os textos que estruturam a fotografia correspondem a séculos de aprimoramento científico. Desde Aristóteles, fazendo uso da camera obscura para a observação de um eclipse no século IV a.C., à divulgação mundial da técnica do daguerreótipo em 1839, a fotografia encontrou subsídios científicos na química do escurecimento dos sais de prata de Albert Le Grand no século XIII, na óptica de Jérome Cardan, que propõe o uso do vidro como lente convergente no século XVI, na mecânica de Daniel Bárbaro, que introduziu o diafragma ao sistema no mesmo século e nas experiências de Niépce, com o betume da Judéia em 1819 (Amar 2007). A própria conceituação da perspectiva artificial como método de transposição da realidade para o plano bidimensional, mesmo parecendo objetiva e isenta, deve ser levada em conta nesta análise da amplitude científica que sustenta a fotografia e, tal como afirma Flusser, prefiguram o seu uso prático.

É por tais razões científicas de estruturação da fotografia que Flusser acredita que imagens técnicas "são dificilmente decifráveis pela razão curiosa de que aparentemente não necessitam ser decifradas”. Ao ressaltar o caráter automático da impressão da imagem técnica sobre uma superfície (que no caso da fotografia se trata do contato entre luz e superfície fotossensível), o que foi permitido pelo constante aprimoramento dos textos científicos, seu significado torna-se óbvio, e a evidência de sua realidade representada (seu caráter perigosamente não-simbólico) a torna simplesmente produto do mundo. E mesmo que o complexo "aparelho-operador" seja uma necessidade - constatação válida até mesmo no caso de fotografias via satélite, ou o robô em Marte, onde ambos devem ser programados por um operador - sua presença não parece interromper o elo entre imagem e significado. É dessa aparente objetividade fotográfica que as pesquisas científicas se servem e que, para Flusser, constituem não uma evidência, mas uma obscuridade, uma vez que quem olha a objetivi- 
dade da imagem técnica não vê imagem representando o mundo (tal como numa pintura em que um sujeito cria seus símbolos), mas sim, textos e conceitos científicos aplicados, exacerbação de uma textolatria. A ciência que se serve da objetividade da imagem técnica, portanto, na verdade cai em redundância de conceitos e tende a não propulsionar o processo de conhecimento e descoberta do mundo, e sim de auto-entendimento de seus textos e conceitos. Para Flusser, a importância histórica da imagem técnica deve ser comparada à escrita. "Textos foram inventados no momento da crise das imagens, a fim de ultrapassar o perigo da idolatria. Imagens técnicas foram inventadas no momento de crise dos textos, a fim de ultrapassar o perigo da textolatria". Cabem às imagens técnicas remagicizarem os textos. Uma intenção implícita que, segundo o autor, precisa ser explicitada (Flusser 1985: 22-23).

A exploração prática do conceito de imagem técnica proposto por Flusser amplia a noção de uso da fotografia de apoio à pesquisa científica. De certa forma, uma prática fotográfica que seja capaz de remagicizar textos científicos ou, em outras palavras, que tente escapar de uma objetividade técnica, pode gerar desconforto no caso de se aproximar demasiadamente de uma produção artística, pois essa aproximação, num certo sentido, consiste na associação entre razão (ciência) e emoção (arte), esferas distintas de percepção e apropriação do mundo. Mas deve-se considerar que as atividades de articulação do conhecimento humano possuem tanto componentes lógicos, racionais e inteligíveis, quanto intuitivos e sensíveis. Arte e ciência, portanto, devem ser consideradas faces do conhecimento que podem se ajustar e se complementar em busca de um entendimento profundo. Tanto que o diálogo entre ambas é uma constante no mundo contemporâneo, uma vez que a arte, mesmo não contradizendo a ciência, tem o potencial de auxiliar, esclarecer e até evidenciar questões que a ciência teria dificuldade em explicar (Zamboini 2006: 22-23). Por meio deste diálogo, a verdade que a ciência busca, portanto, tende a ser mais do que a "verdade conveniente", o simples "assemelhar-se da coisa com o conhecimento” (Heidegger 1995).

\section{Fotografia mais do que ferramenta: buscas e tentativas}

Ao longo de dez anos atuando como fotógrafo do Museu de Arqueologia e Etnologia da Universidade de São Paulo (MAE-USP), o esperado era que a prática fotográfica de apoio às pesquisas desenvolvidas sempre buscasse esta objetividade da imagem técnica. A grande maioria dos trabalhos consistia justamente em apenas representar fotograficamente os artefatos arqueológicos ou etnográficos que eram motivos de análise. Mas foram diversos os momentos em que a "verdade conveniente" esperada pelos pesquisadores ganhou outras formas. Apesar de não poder aqui quantificar e demonstrar de forma exata essa participação mais do que objetiva da fotografia, era evidente que uma outra forma de aproximação com o objeto poderia ser permitida, uma vez que todas as especificidades técnicas de produção fotográfica (controle da luz, profundidade de campo, composição etc.) com freqüência acentuavam o distanciamento entre o que era esperado pelo pesquisador e o que a imagem trazia. Era inevitável que, por mais objetiva que uma câmera fotográfica pudesse ser, não surgissem apelos estéticos que sutilmente revelavam-se inerentes à prática da fotografia.

Mas, mesmo assim, sob a óptica de Flusser, estas experiências estéticas evidentes não poderiam ser consideradas ainda uma prática que escapasse da objetividade dos textos científicos que prefiguram as imagens técnicas, justamente por restringirem-se à manipulação do aparelho fotográfico. Para Flusser, a câmera fotográfica (aparelho) acaba por concentrar toda a atenção de seu operador (funcionário): são caixas pretas que simulam o pensamento humano, graças aos textos científicos, mas dentro de uma possibilidade finita de produção que permuta símbolos contidos em sua memória, ou seja, em seu programa. "O fotógrafo manipula o aparelho, o apalpa, olha para dentro e através dele, a fim de descobrir sempre novas potencialidades. Seu interesse está concentrado no aparelho e o mundo lá fora só interessa em função do programa”. Reduzir a atividade fotográfica à exploração do aparelho significa, aos olhos de 
Flusser, submeter-se ao programa em busca de suas potencialidades já definidas. $\mathrm{O}$ fotógrafo, assim, não trabalha com o aparelho, brinca com ele: e para que a brincadeira não se torne infantil, monótona, "as potencialidades contidas no programa devem exceder à capacidade do funcionário para esgotá-la” (op.cit.: 29-30).

Portanto, uma efetiva forma de busca de uma maior amplitude da participação da fotografia na construção do conhecimento, não deve ser restrita à manipulação do aparelho. Essa forma de ação, que consiste na exploração das possibilidades técnicas da fotografia, apesar de desvelar caminhos estéticos de aproximação com objetos de estudos em pesquisas científicas, ainda significa, segundo Flusser, "não estar empenhado em modificar o mundo, mas em obrigar o aparelho a revelar as suas potencialidades" (op.cit.: 30).

Mas penso em destacar três momentos da prática fotográfica junto ao MAE-USP que considero como tentativas de estender o uso da imagem técnica além da mera manipulação do aparelho e em que a objetividade da fotografia foi "burlada" num certo sentido por meio do diálogo entre arte e ciência. Tomando as palavras de Flusser, são exemplos em que considero que o empenho foi em outra direção que não a busca incessante das potencialidades do aparelho. São três exposições fotográficas que serão destacadas, não só pela forma como abordaram o diálogo entre a prática científica e a fotografia, mas também pela evidência e pela amplitude receptiva que este tipo de modo de comunicar permite atingir.

A primeira, e mais evidente, consistiu na participação do MAE-USP no evento Rencontres Internationales Image et Science promovido pelo Centre National de la Recherche Scietifique de Paris. ${ }^{1}$ Era objetivo do evento buscar manifestações por todo o mundo que pudessem representar o diálogo entre arte e ciência através de imagens. Com o propósito de questionar a objetividade da fotografia, portanto, a proposta

(1) A exposição foi montada no próprio MAE-USP no ano de 2001, e contou com a colaboração de Elly Ferrari, museógrafa, tanto na conceituação quanto no projeto expográfico. A arqueóloga Denise Gomes Cavalcante foi responsável pela curadoria científica. do MAE-USP consistiu simplesmente em apresentar fotografias de uma mesma peça, sob um único ponto de vista, mas sob situações luminosas distintas (de uma única fonte luminosa que se colocava, em cada foto, numa posição diferente), revelando a subjetividade que é inevitavelmente presente na objetividade da fotografia científica (Fig. 1). Um dos textos da exposição trazia a seguinte citação: "a foto pode ser uma prova instrutiva e irrefutável. É tão evidente que não é preciso insistir nisso. Mas, ao mesmo tempo, ocorre com freqüência que não se sabe bem o que ela prova". (Henri Van Lier 1981 apud Dubois 1993: 84). A redundância da reprodução de uma mesma peça entra em confronto com a variação luminosa revelando fotografias distintas. Em outras palavras, o que se procurou com esta exposição foi justamente demonstrar a autonomia da fotografia em construir novas formas de apropriação e percepção de uma realidade. A tão desejada isenção referente à objetividade fotográfica científica sempre dependerá de intervenções subjetivas. Via-se o mesmo artefato, mas imagens distintas: por mais que pareça uma proposta óbvia, a constatação do distanciamento entre fotografia (imagem) e o objeto (realidade) parece uma questão fotográfica que nunca se esgotará e sempre deverá ser discutida, sobretudo numa esfera de atuação científica em que se preza a objetividade do aparato. Questão esta fundamental para a investigação de significados em imagens técnicas que perigosamente parecem não exigir decifração, tal como já apontado por Flusser.

A segunda exposição, intitulada "Vivências e Memória”, surgiu como parte de uma oficina educativa para a terceira idade, e consistiu em apresentar fotografias de objetos dos participantes que trouxeram suas peças que consideravam mais valoradas na história de seus cotidianos pessoais. ${ }^{2}$ Produzidas dentro dos mesmos

(2) A exposição fotográfica concluiu os trabalhos de Judith Mader Elazari, educadora do MAE-USP, na edição de 2003 da oficina oferecida ao público da terceira idade. A montagem contou com a colaboração de Maria Aparecida dos Santos, designer gráfica, que também contribuiu com o projeto expográfico. 

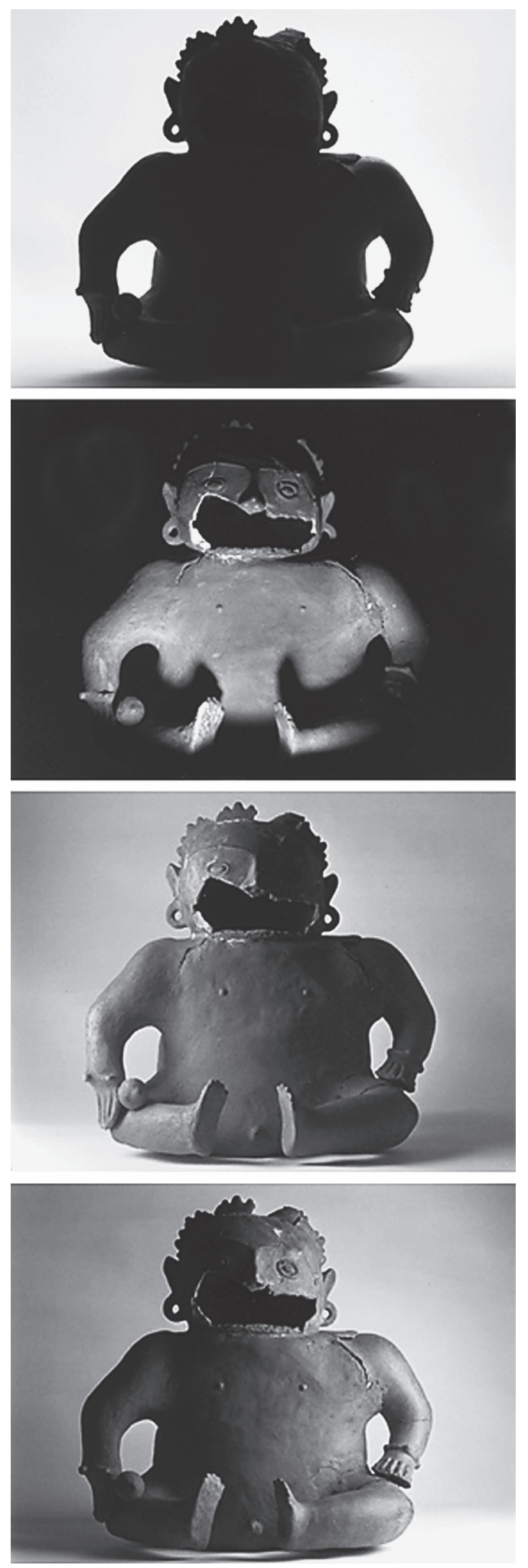

Fig.1. Imagens de urna antropomorfa (Santarém) que integraram a exposição fotográfica do MAE-USP no evento mundial Image et Sciense em 2001.

padrões técnicos a que são submetidos os acervos arqueológicos e etnográficos do Museu, as fotografias foram expostas com objetivo claro de evidenciar a importância de um acervo na construção da memória, mas não pela evidência de peças milenares, e sim por meio de objetos do cotidiano contemporâneo. Trocam-se as ferramentas pré-históricas, as estatuetas de cerâmica amazônicas ou artefatos de arte plumária por brinquedos, cadernos escolares ou enfeites de sala de estar. E é justamente nesta troca que reside a razão para destacar o evento como busca de uma remagicização dos textos científicos, sejam eles arqueológicos ou museológicos (Fig. 2).

Por fim, "Cidade antiga em cena", que trazia fotografias de uma expedição audiovisual realizada na Itália, em que o objetivo era também registrar as reminiscências do passado que permeiam as cidades contemporâneas naquele país. ${ }^{3}$ Tratava-se de uma trabalho de campo arqueológico, mas com o objetivo primordial de se trazer imagens em vídeo e fotográficas. A exposição resultante contou com dois módulos. Num, viam-se fotografias de uma peça teatral encenada num legítimo teatro grego ${ }^{4}$ (Fig. 3). No outro módulo, foram exibidas 147 imagens, no tamanho de $11 \mathrm{~cm} \times 17 \mathrm{~cm}$ cada, dispostas individualmente e separadas por pequenas lacunas de $1,5 \mathrm{~cm}$, em sete linhas e 21 colunas, perfazendo um mosaico de $320 \mathrm{~cm}$ x 85 $\mathrm{cm}$. Cada fotografia do mosaico poderia trazer um motivo apenas ou, por meio de duas, quatro ou nove fotografias, compor apenas um único motivo, e nesses casos, o distanciamento de 1,5 $\mathrm{cm}$ entre as partes representava lacunas na imagem composta (a descrição detalhada torna-

(3) Expedição promovida pelo LABECA (Laboratório de Estudos da Cidade Antiga) do MAE-USP, em maio de 2007. A montagem e concepção contou com a colaboração de Maria Aparecida dos Santos, designer gráfica, e textos de Maria Beatriz Borba Florenzano, Elaine Farias Veloso Hirata e Lilian de Angelo Laki. (4) Encenação de As Traquinias de Sófocles, no teatro grego de Siracusa, em 12 de maio de 2007. 

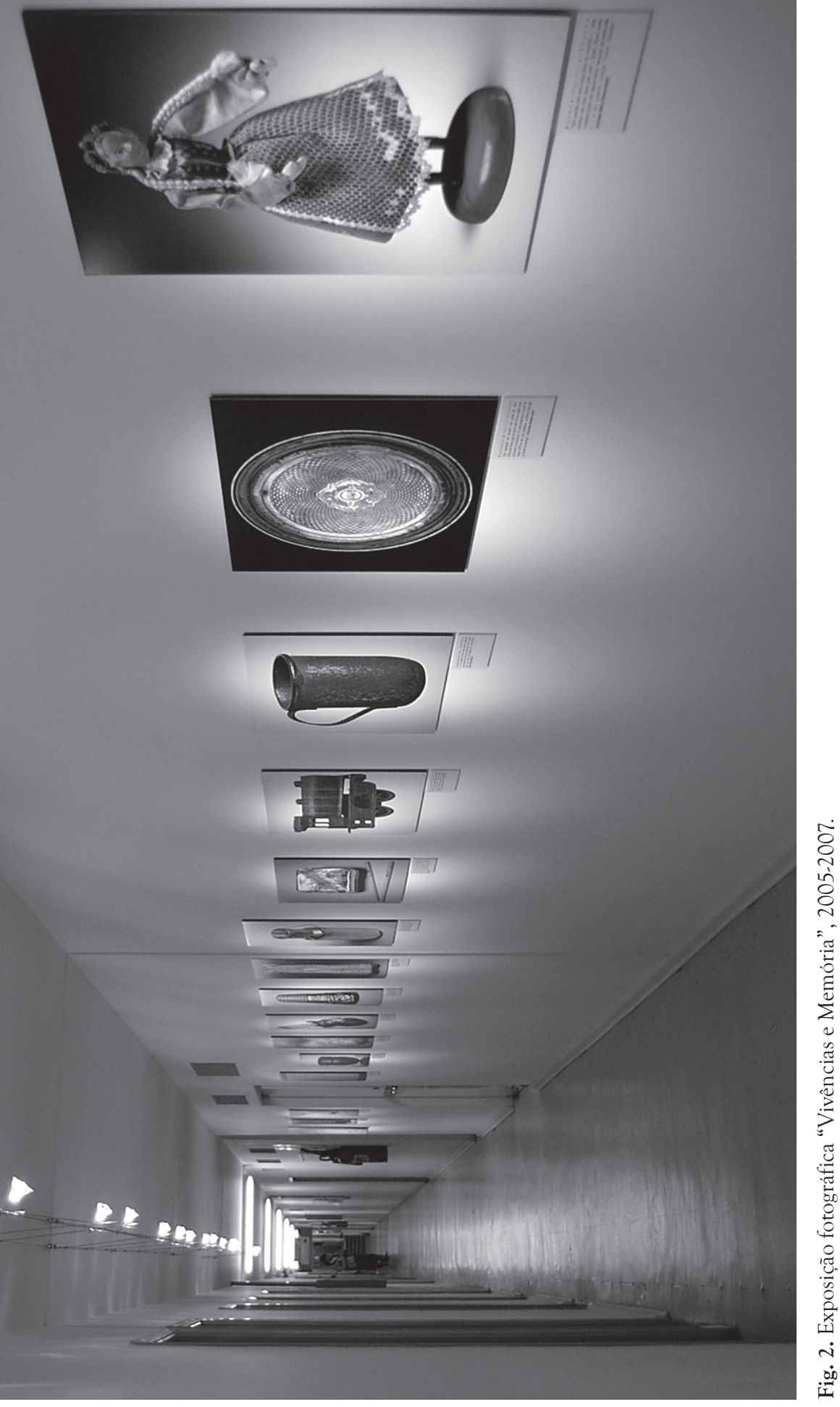
se fundamental para sustentar o questionamento - ver Fig. 4). Além dos sítios arqueológicos e dos trabalhos referentes à documentação audiovisual, o mosaico trazia imagens de diversos motivos: fauna, flora, texturas, gente, cotidiano, comércio, ou seja, uma amostra da experiência visual vivenciada no trabalho de campo. A intenção aparentemente presente neste mosaico seria a de compartilhar tudo aquilo que foi visto e compactuado com a câmera fotográfica. Mas o objetivo foi justamente o contrário: procurou-se demonstrar a incapacidade da câmera em dar conta desta experiência visual, a incompetência do ato de fotografar frente ao ato de olhar. As lacunas entre as imagens (rasgos nas imagens), demonstrando que alguns motivos estão fragmentados e com falhas de informação, aliadas à confusão visual representada pela disposição de imagens de mesmo tamanho, que ora são peças de um conjunto que forma uma imagem maior, ora são imagens singulares, nada mais são do que a constatação da complexidade do exercício de olhar o mundo que a câmera fotográfica não consegue atingir. $\mathrm{O}$ inesgotável programa contido no aparelho é sugerido de forma denunciadora pelo mosaico, e, ao mesmo tempo em que evidencia a potencialidade da imagem técnica, sugere também sua fragilidade frente à potencialidade do olhar.

\section{Conclusão}

Os três exemplos citados possuem uma linha comum de atuação que pode ser entendida a partir das considerações de Flusser: as três

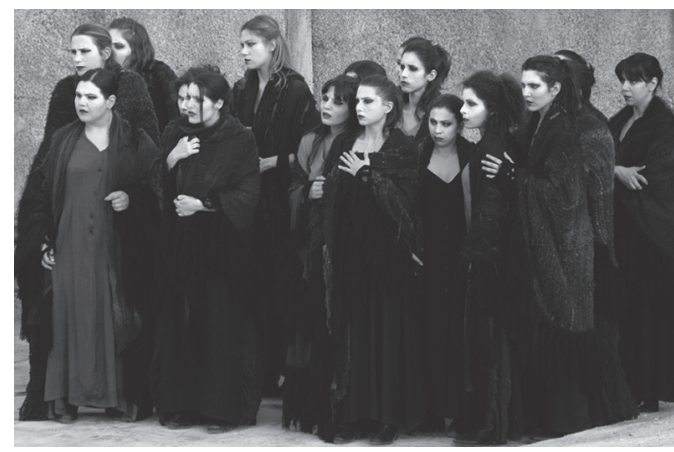

Fig. 3. Fotografias da encenação de As Traquínias, de Sófocles, no teatro grego de Siracusa, Itália, em maio de 2007.

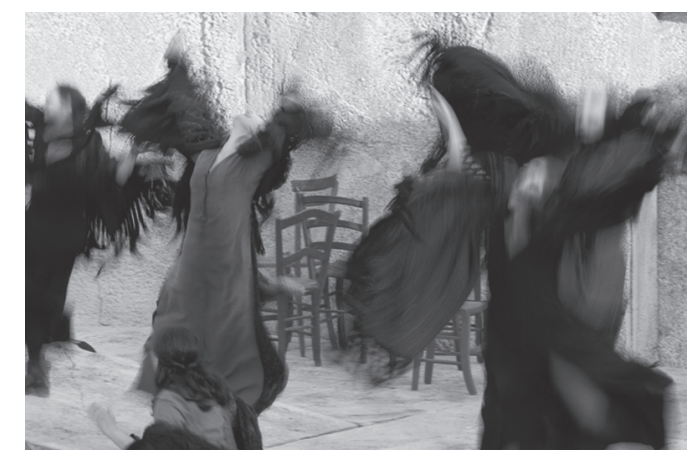

exposições fotográficas buscaram burlar a sobreposição da câmera sobre o sujeito, ou nas palavras do autor, buscaram o "clareamento da caixa preta” (relação funcionário-aparelho).

Viu-se, através do pensamento de Flusser, que o uso da objetividade fotográfica pode ser muito mais uma imposição não evidente do que uma opção numa determinada pesquisa científica, e isso suscita algumas questões: qual o real papel das imagens técnicas na construção do conhecimento? Seriam elas propulsionadoras (trazendo descobertas, novas formas de percepção) ou inócuas (redundância de uma textolatria)?

O que se buscou em cada uma das exposições fotográficas, apresentadas como exemplo, foi justamente promover a expansão das possibilidades de se pensar e produzir a fotografia não só como mera ferramenta baseada na sua capacidade inegável de refletir por meio de imagens as teorias, conceitos ou dados científicos de uma determinada pesquisa, mas também, e principalmente, como mecanismo questionador de possíveis conclusões pré-estabelecidas e difusor de novas formas de percepção e métodos de aproximação com objetos de estudos diversos.

A conceituação de imagem técnica sugerida por Flusser abre caminho para questionamentos a respeito da objetividade inerente à fotografia e, conseqüentemente, abre espaço para que seja possível a incrementação de suas possibilidades como tecnologia fundamental na busca do conhecimento do mundo e nos processos de formação de culturas. Dentro das categorias de classificação semiótica sugeridas por Charles Peirce (2005), por exemplo, Flusser é o único autor que reconhecidamente ultrapassa a idéia de índice e ícone, elevando a 

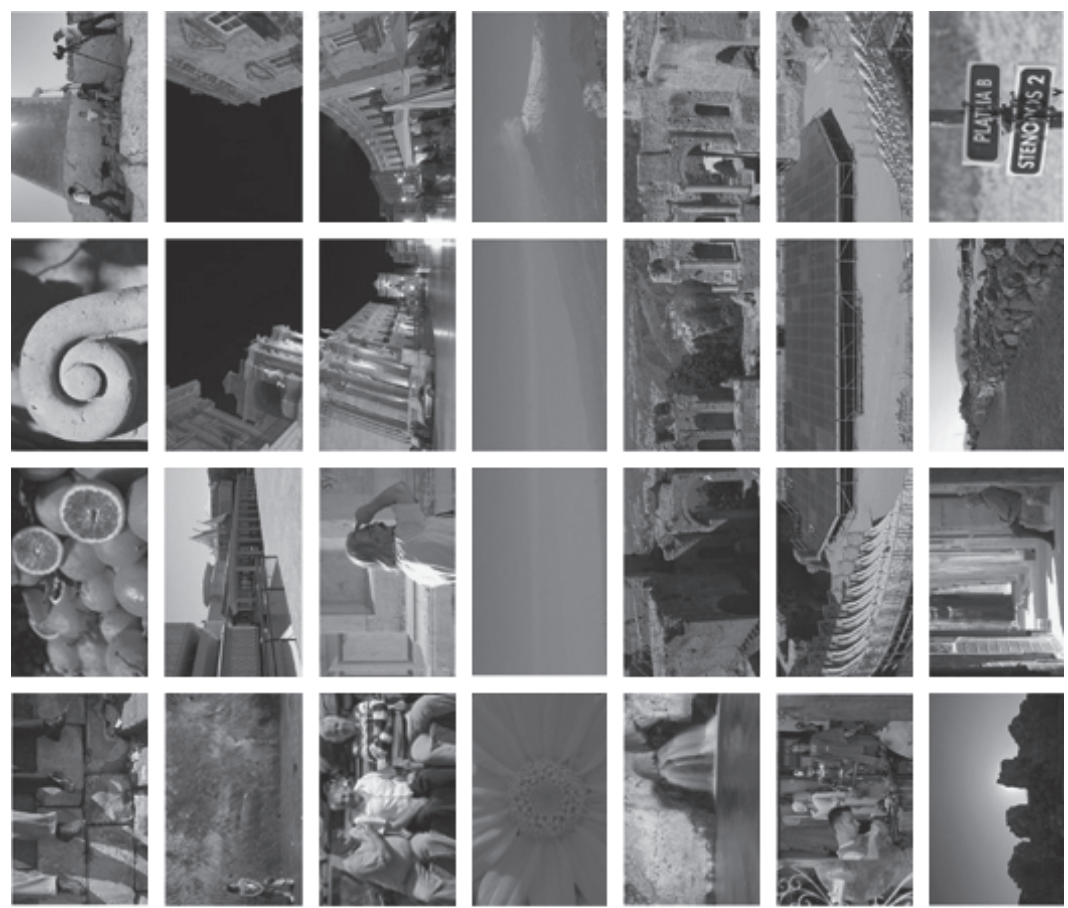

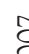
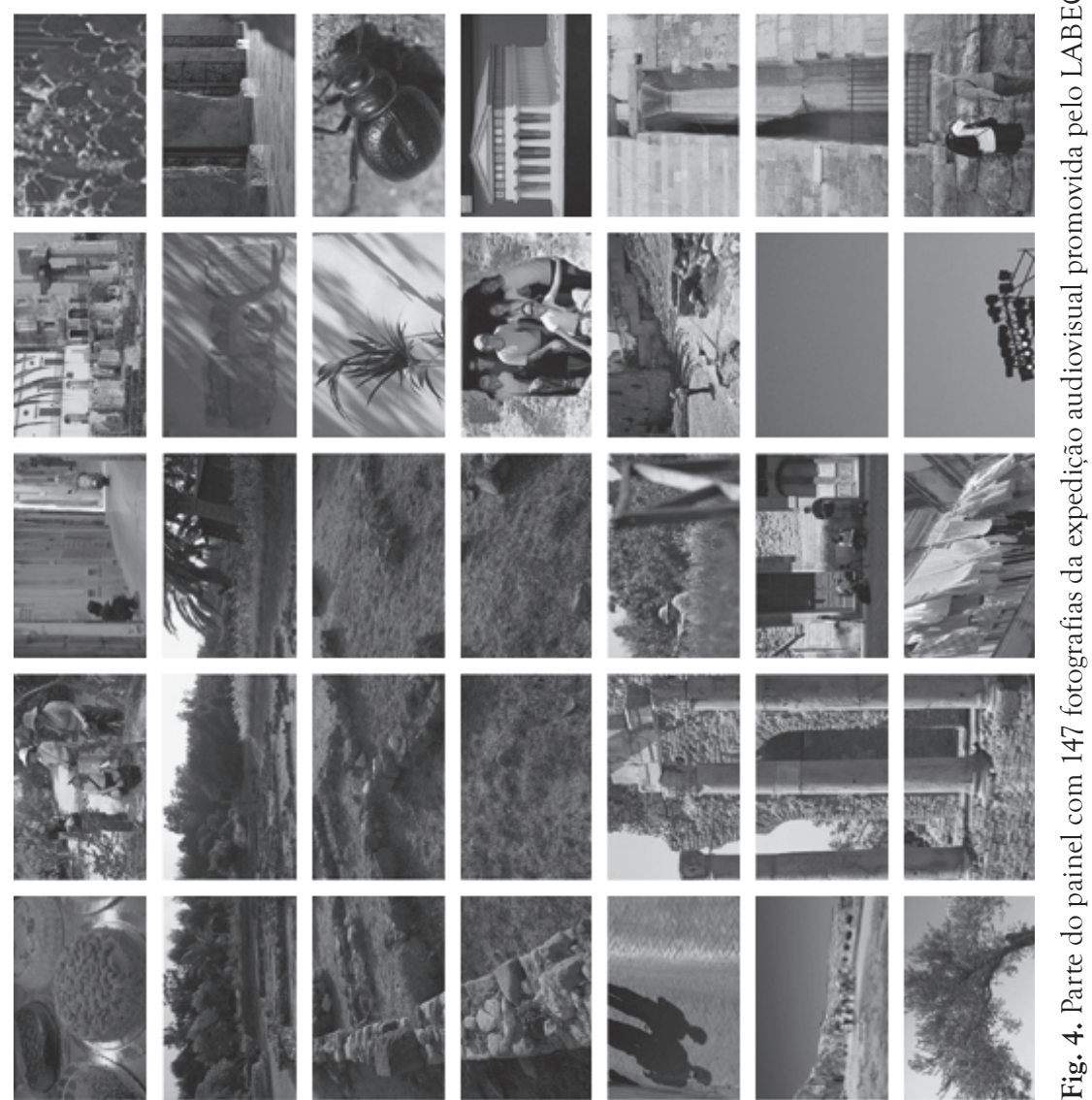
fotografia a símbolo. Por materializar textos científi$\cos$, o que a fotografia produziria, portanto, seria a expressão de conceitos, entendidos, sobretudo, dentro de uma esfera sustentada pela dialética entre a razão, lógica e objetividade (ciência), e a pluralização do significado de expressões subjetivas (arte). Desta forma, sua atuação seria muito mais complexa, visto seu potencial em expressar conceitos gerais e abstratos (Machado 1998). É nessa condição que a noção de texto científico, que conceitua e estrutura a fotografia, pode ir muito além do que aqueles nos âmbitos da física, química ou mecânica.
A fotografia congrega não só as ciências que a estruturam, mas também as que dela fazem uso. Atuando como ponto de convergência de conhecimentos diversos, e principalmente por fazê-lo através da produção de imagens, estas tão presentes e decisivas na estruturação da cultura contemporânea, a fotografia, como uma prática já consagrada, tem o potencial também de se delinear como um possível método de busca de conhecimento e entendimento de uma dada realidade, objetivo primeiro de qualquer ciência.

SOUZA E SILVA, W. Between scientific photographs and science of photography. Revista do Museu de Arqueologia e Etnologia, São Paulo, 17: 435-444, 2007.

Abstract: Regarding some projects developed at the Museum of Archaeology and Ethnology at the University of São Paulo, this text presents some inquires about the photography as tool for scientific research and proposes its use in a wider way through the analysis of its configuration as technical image.

Keywords: Photography - Science - Technology - Technical images.

\section{Referências bibliográficas}

AMAR, P-J.

2007 História da Fotografia. Lisboa: Edições 70.

CAVALHEIRO, E.A.

2007 A nova convergência da ciência e da tecnologia. Revista Novos Estudos. São Paulo: Cebrap, julho: 23-30.

DUBOIS, P.

1993 O ato fotográfico e outros ensaios. Campinas: Papirus.

2004 Máquinas de imagens: uma questão de linha geral. In: Cinema, vídeo, Godard. São Paulo: Cosac \& Naif: 31-67.

FLUSSER, V.

1985 Filosofia da caixa preta. São Paulo: Hucitec. HEIDEGGER, M.

1995 Sobre a essência da verdade. Porto: Porto Editora.
LIER, H. VAN

1981 Philosophie de la photographie. Bruxelas: Palais des Beaux-Arts.

MACHADO, A.

2002 As imagens técnicas: da fotografia à

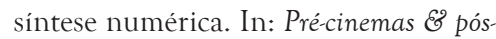
cinemas. Campinas: Papirus: 220-234.

2003 A fotografia como expressão do conceito. Disponível em www.studium.iar.unicamp/2. Acesso em dezembro de 2003.

PEIRCE, C.S.

2005 Semiótica. São Paulo: Perspectiva.

ZAMBONI, S.

2006 A pesquisa em arte: um paralelo entre arte e ciencia. Campinas: Autores Associados. 